\title{
Trends in mortality rates of cutaneous melanoma in East Asian populations
}

\author{
Ling Chen ${ }^{\text {Corresp.. }} 1,2$, Shaofei Jin ${ }^{\text {Corresp. } 3}$ \\ ${ }^{1}$ Zhongshan School of Medicine, Sun Yat-sen University, Guangzhou, China \\ 2 Immunotherapy Institutes, Fujian Medical University, Fuzhou, China \\ 3 Northeast Institute of Geography and Agroecology, Chinese Academy of Sciences, Changchun, China \\ Corresponding Authors: Ling Chen, Shaofei jin \\ Email address: chenlsysu@hotmail.com, jinsf@tea.ac.cn
}

The incidence of cutaneous melanoma (CM) has rapidly increased over the past four decades. CM is often overlooked in East Asian populations due to its low incidence, despite East Asia making up $22 \%$ of the world's population. Since the 1990 s, Caucasian populations have seen a plateau in CM mortality rates, however, there is little data investigating the mortality rates of CM in East Asian populations. In this study, the World Health Organization Mortality Database with the joinpoint regression method, and a generalized additive model were used to investigate trends in age standardized mortality rates (ASMRs) of CM in four East Asia regions (Japan, Republic of Korea [Korea], China: Hong Kong [Hong Kong], and Singapore) over the past six decades. In addition, mortality rate ratios by different variables (i.e. sex, age group, and region) were analyzed. Our results showed ASMRs of CM in East Asia significantly increased non-linearly over the past six decades. The joinpoint regression method indicated women had greater annual percentage changes than men in Japan, Korea, and Hong Kong. Men had significantly greater mortality rate ratio $(1.51,95 \%$ confidence interval $[95 \% \mathrm{Cl}]: 1.48-1.54)$ than women. Mortality rate ratios in 30-59 and 60+ years were significant greater than in the 0-29 years. Compared to Hong Kong, mortality rate ratio was $0.72(95 \% \mathrm{Cl}: 0.70-0.74)$ times, $0.73(95 \% \mathrm{Cl}: 0.70-0.75)$ times, and $1.02(95 \% \mathrm{Cl}: 1.00-1.05)$ times greater in Japan, Korea, and Singapore, respectively. Although there is limited research investigating CM mortality rates in East Asia, results from the present study indicate that there is a significant growth in the ASMRs of CM in East Asian populations, highlighting a need to raise awareness of $\mathrm{CM}$ in the general population. 
2

3 Ling Chen ${ }^{1,2}$, Shaofei Jin ${ }^{3 \#}$

4 1. Zhongshan School of Medicine, Sun Yat-sen University, Guangzhou, China

5 2. Immunotherapy Institutes, Fujian Medical University, Fuzhou, China

63 . Northeast Institute of Geography and Agroecology, Chinese Academy of Sciences,

$7 \quad$ Changchun, China

8

9 Short title: Cutaneous Melanoma in East Asia

10 \# Co-corresponding authors.

11 Ling Chen: chenlsysu@hotmail.com

12 Shaofei Jin: jinsf@tea.ac.cn

13 


\section{Abstract}

The incidence of cutaneous melanoma $(\mathrm{CM})$ has rapidly increased over the past four decades. CM

17 is often overlooked in East Asian populations due to its low incidence, despite East Asia making up $22 \%$ of the world's population. Since the 1990 s, Caucasian populations have seen a plateau in CM mortality rates, however, there is little data investigating the mortality rates of CM in East Asian populations. In this study, the World Health Organization Mortality Database with the joinpoint regression method, and a generalized additive model were used to investigate trends in age standardized mortality rates (ASMRs) of CM in four East Asia regions (Japan, Republic of Korea [Korea], China: Hong Kong [Hong Kong], and Singapore) over the past six decades. In addition, mortality rate ratios by different variables (i.e. sex, age group, and region) were analyzed.

Our results showed ASMRs of CM in East Asia significantly increased non-linearly over the past

26 six decades. The joinpoint regression method indicated women had greater annual percentage

27 changes than men in Japan, Korea, and Hong Kong. Men had significantly greater mortality rate

28 ratio $(1.51,95 \%$ confidence interval $[95 \% \mathrm{CI}]: 1.48-1.54)$ than women. Mortality rate ratios in

$2930-59$ and $60+$ years were significant greater than in the 0-29 years. Compared to Hong Kong,

30 mortality rate ratio was $0.72(95 \% \mathrm{CI}: 0.70-0.74)$ times, $0.73(95 \% \mathrm{CI}: 0.70-0.75)$ times, and 1.02

$31(95 \%$ CI: 1.00-1.05) times greater in Japan, Korea, and Singapore, respectively. Although there is

32 limited research investigating CM mortality rates in East Asia, results from the present study

33 indicate that there is a significant growth in the ASMRs of CM in East Asian populations,

34 highlighting a need to raise awareness of CM in the general population. 
36 Keywords: cutaneous melanoma, East Asia, mortality, GAM, ultraviolet radiation, skin cancer 37 


\section{Introduction}

40 Over the past four decades, cutaneous melanoma $(\mathrm{CM})$ has been one of the most rapidly increasing

41 cancers globally (Garbe \& Leiter 2009; Giblin \& Thomas 2007; Nikolaou \& Stratigos 2014).

42 Numerous studies investigated the incidence and mortality rates of CM in Caucasian populations

43 (Barbaric et al. 2016; Wallingford et al. 2013; Bristow et al. 2013; Duschek et al. 2013; Sneyd \&

44 Cox 2013), however, only a small number of studies exist focusing on the incidence and mortality

45 rates of CM in East Asian populations. Research investigating average annual age-standardized

46 incidence rate of CM in Japan was 0.25 per 100000 for men, and 0.20 per 100000 for women

47 between 1964 and 1995 (Tanaka et al. 1999). In China: Hong Kong (Hong Kong), the mean

48 incidence of $\mathrm{CM}$ between 1983 and 2002 was 0.8 per 100000 for men and 0.6 per 100000 for

49 women, but the mortality rate significantly increased during this time (Makredes et al. 2010). In

50 Singapore, the annual age-standardized incidence of all skin cancer increased between 1968 and

511997 (Koh et al. 2003) and in Beijing and Shanghai, the mortality of CM increased between 1988

52 and 2007 (Zeng et al. 2012).

54 Although mortality rates of CM in East Asia are relatively low, East Asians constitute 22\% of the

55 world's population (United Nations, 2015) therefore, identifying trends in mortality and the

56 characteristics of this disease in this population is imperative. Risk factors affecting mortality rates

57 of CM include ultraviolet (UV) radiation exposure (Nikolaou \& Stratigos 2014), which is highly 
58 variable in this geographically spread region. Aging is another risk factor affecting mortality rates

59 of CM (Simard et al. 2012). East Asia, like the rest of the world, has a rapidly aging population,

60 which has serious implications for sustainable social development (Goh 2005; Oizumi 2013). In

$612015,26 \%$ of population in Japan and 13\% of population in Republic of Korea (Korea) were aged

6265 or older (World Bank Datasets, 2016). Finally, there are sex-related differences in CM mortality

63 rates (Lasithiotakis et al. 2008) with men being at a greater risk of developing and dying from CM

64 (Luk et al. 2004; Makredes et al. 2010). In Hong Kong, the female-to-male incidence rate is 1:1.22

65 (Luk et al. 2004), and the mortality rate is 1:1.35 (Makredes et al. 2010). Few studies exist

66 investigating the cumulative effects of risk factors on the mortality rate of $\mathrm{CM}$ in East Asian

67 populations; this study aims to address this gap.

68

69 To address this research gap, long-term trends in CM mortality in four regions including: Japan,

Korea, Hong Kong, and Singapore, were analyzed using the joinpoint regression method and

71 Generalized Additive Model (GAM) over the past six decades. The specific aims of this study are to identify trends in mortality rates of $\mathrm{CM}$ and the mortality rate ratio of $\mathrm{CM}$ by sex and age in four specific East Asian regions over the past six decades. 
Methods and Materials

76

77

78

79

80

81

82

83

84

\section{Data source}

Mortality data from East Asia were obtained from the World Health Organization Cancer Mortality Database (World Health Organization). This database is managed by the Section of Cancer Surveillance at the International Agency for Research on Cancer. Age standardized mortality rates (ASMRs) and deaths caused by CM in four East Asia regions were extracted over different periods: Japan (1955-2013), Korea (1985-2013), Hong Kong (1966-2013), and Singapore (1968-2014). The records were defined according to the International Classification of Diseases (ICD) codes as ICD-8 172, ICD-9 172 and ICD-10 C43. The ASMRs data were imported directly from the database and registered by sex and age. ASMRs are calculated as a weighted mean based on the world standard population in age-specific rates (Segi, 1960), and are defined as the total number of CM deaths per 100,000 persons. The data were further categorized into three age groups: 0-29 years, 30-59 years, and 60+ years. See Supplemental Information 1 for the detailed dataset.

\section{Statistical analysis}

The joinpoint regression method and Generalized Additive Model (GAM) were performed to investigate the trends of ASMRs in four East Asian regions over the past six decades. The joinpoint regression method detects change points for trend data (i.e. mortality rates of cancer). This method 
95 starts with a minimum number of joinpoint (default, 0 ), and adds more jointpoints to the models if more statistically significant linear changes $(P<0.05)$ are found after testing using a Monte Carlo Permutation method. To avoid the occurrences of spurious changes in trends, the maximum jointpoints were set to three (Baade et al. 2012). Finally, the model will return the estimated parameters and their statistical power values among the joinpoints. All joinpoint analysis was conducted using joinpoint regression software (Version 4.3.10 - April 19, 2016), downloaded from the Surveillance Research Program of the US National Cancer Institute (http://surveillance.cancer.gov/joinpoint/). For further details on this method, see Kim et al. (2000). In the present study, this method is used to analyze average annual percentage changes (AAPC) and annual percentage changes (APC) of ASMRs between men and women for each region.

GAM was applied to investigate the relationship between ASMRs of CM and other factors, including gender, age group, year, and region. GAM is a more flexible statistical model to analyze nonlinear relationships between variables. GAMs were conducted using the $m g c v$ package of $\mathrm{R}$ programming (R Core Team 2016). Assuming the deaths follow a Poisson distribution, the GAM models were expressed as follows:

For the four regions, the model was described as follows (Equation 1):

$$
\log \left(\text { ASMRs }_{i}\right)=a+\mathrm{s}\left(\text { year }_{i}\right)+\text { factor }\left(\operatorname{age~group~}_{i}\right)+\text { factor }\left(\operatorname{sex}_{i}\right)+\text { factor }\left(\operatorname{region}_{i}\right)+\varepsilon_{i} \varepsilon_{i} \sim N\left(0, \sigma^{2}\right)
$$


116

117 For each region, the model was described as follows(Equation 2):

118

119

120

121

122

123

124

125

126

127

128

129

130

131

132

133

$\log \left(\right.$ ASMRs $\left._{i}\right)=a+\mathrm{s}\left(\right.$ year $\left._{i}\right)+$ factor $\left(\operatorname{age~group~}_{i}\right)+$ factor $\left(\operatorname{sex}_{i}\right)+\varepsilon_{i} \varepsilon_{i} \sim N\left(0, \sigma^{2}\right)$ in R, and Fig. S9 for simplified explanation. 6 of female, and 30-59 years age group, and Hong Kong, respectively.

where, ASMRs refers to age standardized mortality rate of the year $i$; year refers to the year; age group, sex, and region refers to nominal explanatory variables of different age groups (three levels), gender (two levels: male and female), and the four regions (four levels), respectively. $a$ refers to the intercept; Ei refers to the error term. The $s\left(\right.$ year $\left._{\mathrm{i}}\right)$ is the smoothing function to show the trends in AMSRs over the periods. See Wood (2006) for technical detail of GAM implementing

\section{Mortality rate ratios of cutaneous melanoma by different explanatory variables}

Mortality rate ratios of $\mathrm{CM}$ by sex, age group, and regions are obtained from estimated parameters of explanatory variables in the GAMs, and express the relative contribution of different explanatory variables to the ASMRs. The mortality rate ratios are set to references for the factor 


\section{Results}

\section{Annual percentage changes of cutaneous melanoma in East Asia}

137

138 Table 1: Joinpoint regression analysis of age-standardized mortality rate of cutaneous melanoma in four Asia regions 139

\begin{tabular}{|c|c|c|c|c|c|c|c|c|c|c|c|}
\hline \multirow{2}{*}{ Region $^{\mathrm{a}}$} & \multirow{2}{*}{ Sex } & \multirow{2}{*}{ Period } & \multirow{2}{*}{ Average ASMR $^{\mathrm{b}}$} & \multirow{2}{*}{$\operatorname{AAPC}^{\mathrm{c}}(95 \% \mathrm{CI})^{\mathrm{d}}$} & \multicolumn{2}{|c|}{ Trend 1} & \multicolumn{2}{|c|}{ Trend 2} & \multicolumn{2}{|c|}{ Trend 3} & \multirow{2}{*}{$\begin{array}{c}\text { AAPC }(95 \% \\
\text { CI })^{\mathrm{f}}\end{array}$} \\
\hline & & & & & Years & $\mathrm{APC}^{\mathrm{e}}(95 \% \mathrm{CI})$ & Years & APC $(95 \% \mathrm{CI})$ & Years & APC $(95 \% \mathrm{CI})$ & \\
\hline Japan & Male & $1955-2013$ & 0.18 & $2.5(2.1,2.8)^{\mathrm{g}}$ & $1955-1973$ & $7.4(6.5,8.4)$ & $1973-2013$ & $0.3(0.0,0.6)$ & & & $0.3(0.0,0.6)$ \\
\hline Japan & Female & $1955-2013$ & 0.12 & $2.6(2.1,3.2)$ & $1955-1974$ & $6.7(5.1,8.4)$ & $1974-2013$ & $0.7(0.4,0.9)$ & & & $0.7(0.4,0.9)$ \\
\hline Korea & Male & $1985-2013$ & 0.23 & $7.3(0.7,14.4)$ & $1985-1989$ & $0.1(-16.6,20.1)$ & 1989-1992 & $43.7(-19.4,156.0)$ & $1992-2013$ & $4.3(2.8,5.9)$ & $4.3(2.8,5.9)$ \\
\hline Korea & Female & $1985-2013$ & 0.16 & $7.4(5.6,9.2)$ & $1985-2013$ & $7.4(5.6,9.2)$ & & & & & $7.4(5.6,9.2)$ \\
\hline Hong Kong & Male & $1966-2013$ & 0.28 & $-0.5(-3.8,2.9)$ & 1966-1969 & $-28.4(-57.6,20.9)$ & $1969-2013$ & $1.8(0.9,2.7)$ & & & $1.8(0.9,2.7)$ \\
\hline Hong Kong & Female & $1966-2013$ & 0.2 & $2.4(1.4,3.4)$ & $1966-2013$ & $2.4(1.4,3.4)$ & & & & & $2.4(1.4,3.4)$ \\
\hline Singapore & Male & $1968-2014$ & 0.31 & $-0.4(-1.7,0.9)$ & $1968-2014$ & $-0.4(-1.7,0.9)$ & & & & & $-0.4(-1.7,0.9)$ \\
\hline Singapore & Female & $1968-2014$ & 0.23 & $-0.2(-1.5,1.0)$ & $1968-2014$ & $-0.2(-1.5,1.0)$ & & & & & $-0.2(-1.5,1.0)$ \\
\hline
\end{tabular}

140 Notes:

141 a: Korea: Republic of Korea; Hong Kong: China: Hong Kong;

142 b: ASMR: Age standardized mortality rate, per 100,000 persons;

143 c: AAPC: Average annual percentage changes over the entire period;

144 d: 95\%CI: 95\% confidence interval;

145 e: APC: Annual percentage changes;

146 f: AAPC over the last five years;

$147 \mathrm{~g}$ : Bold values represents joinpoint is significantly different from zero at $P<0.05$ level. 
149 Table 1 showed the average ASMRs for male was greater than for female in each region over past 150 decades. Moreover, the average ASMRs increased from the northernmost region to the

151

152

153

154

155

156

157

158

159

160

161

162

163

164

165

166

167

\section{.}

southernmost region for both genders. Female conducted greater AAPC than male in the four regions except Singapore. ASMRs increased significantly for both sexes in Japan and Korea over the entire periods (Table 1). For details, ASMR was increasing continuously since 1985 by $7.4 \%$ (95\% confidence intervals $[95 \% \mathrm{CI}]: 5.6 \%-9.2 \%)$ yearly in Korea female (Table 1). Further, although more than one joinpoints were detected for both Japanese and Korea male, all APCs in the last trends were significant greater than zero. For the other two regions, only significantly growth in ASMRs was found in female of Hong Kong. For the regional differences in APCs, Korea has the greatest APCs among the four regions, while no changes were found in Singapore. Furthermore, significant increases in the ASMRs were found over the last five years in all regions except Singapore. Displays of joinpoint regression analyses for male and female in the four regions were shown in Fig. S1-8 (Supplemental Information 2). In addition, the GAM showed the overall ASMRs of East Asia population had a significant non-linear growth over the past six decades (Fig. S9).

\section{Mortality rate ratios of cutaneous melanoma by sex, age group, and region in East Asia}
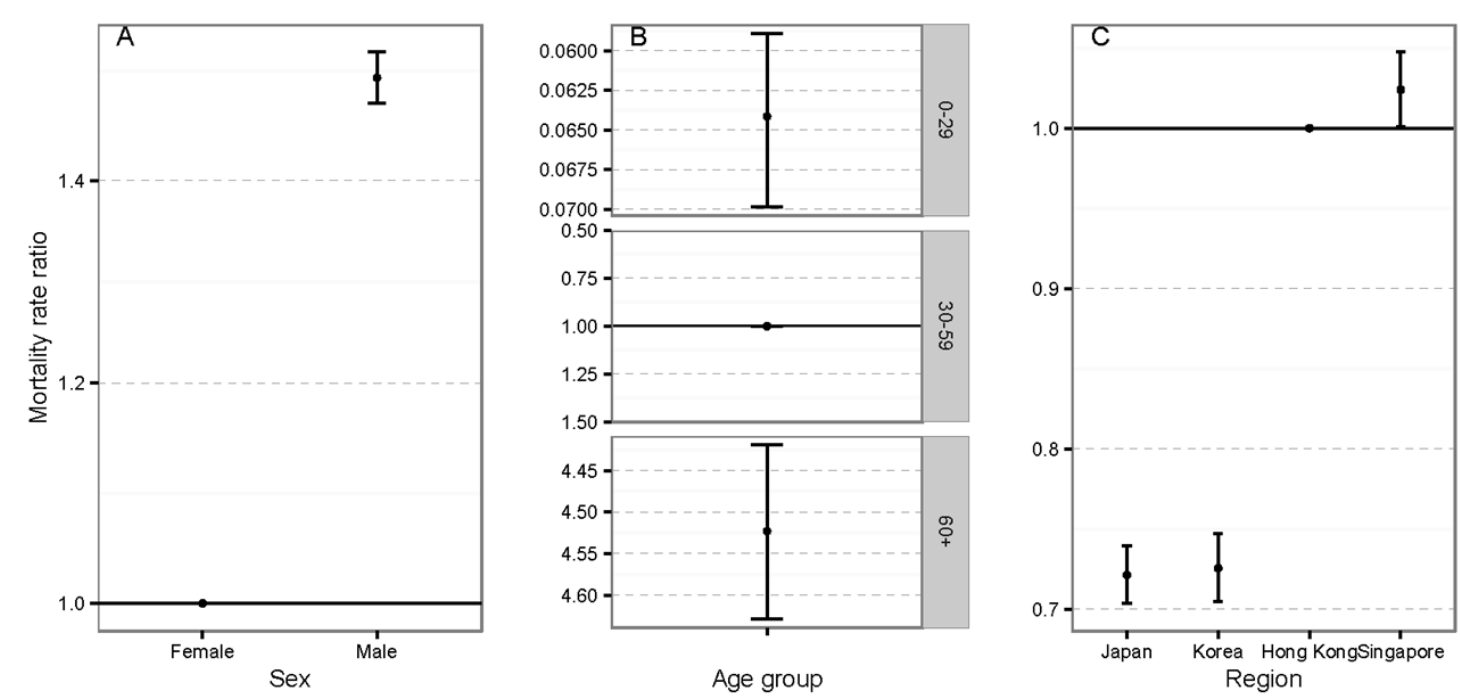

168 169

Figure 1: Mortality rate ratios of cutaneous melanoma by (A) sex, (B) age group, and (C) region 
170 in East Asia. The error bars represent 95\% confidence intervals. 0-29: deaths aged 0-29 years; 171 30-59: deaths aged 30-59 years; 60+: deaths aged 60+ years. The mortality rate ratios of male,

174 Significant differences in mortality rate ratio of different explanatory factors were found among women (1.51; 95\%CI: 1.48-1.54; $P<0.001$, Chi.sq=1970, Chi-square test, same with below, Fig.

Finally, significant differences in mortality rate ratio were detected among the four regions (Fig.

$1 \mathrm{C}, P<0.001$, Chi.sq $=1254)$. Mortality rate ratio in Japan $(0.72 ; 95 \% \mathrm{CI}: 0.70-0.74)$, Korea with Hong Kong.

Table 2: Mortality rate ratio (with $95 \%$ confidence intervals) of cutaneous melanoma by sex and age group in different regions.

\begin{tabular}{lcccc}
\hline & Japan & Korea & Hong Kong & Singapore \\
\hline Sex & & & & \\
Female (reference) & 1.00 & 1.00 & 1.00 & 1.00 \\
\hline Male & $* 1.54(1.48,1.59)$ & $* 1.52(1.45,1.60)$ & $* 1.57(1.52,1.62)$ & $* 1.43(1.38,1.47)$ \\
\hline & $p<0.001$ & $p<0.001$ & $p<0.001$ & $p<0.001$ \\
\hline Age group (years) & & & & \\
$0-29$ & $* 0.08(0.07,0.09)$ & $* 0.07(0.05,0.08)$ & $* 0.06(0.05,0.07)$ & $* 0.06(0.05,0.07)$ \\
\hline $30-59$ (reference) & 1.00 & 1.00 & 1.00 & 1.00 \\
\hline $60+$ & $* 4.39(4.18,4.60)$ & $* 4.44(4.18,4.71)$ & $* 4.75(4.55,4.96)$ & $* 4.46(4.28,4.65)$ \\
\hline & $p<0.001$ & $p<0.001$ & $p<0.001$ & $p<0.001$ \\
\hline
\end{tabular}

189

190

Notes:

191

$*_{p}<0.001$. 
193 In addition, we analyzed the specific mortality rate ratios by sex and age group in different regions 194 due to their geographic locations. Table 2 showed men had significantly greater mortality rate 195 ratios than women $(95 \% \mathrm{CIs}>1)$. Among the four regions, the greatest mortality rate ratio was 196 found in Hong Kong (1.57; 95\%CI: 1.52-1.62), while the lowest was in Singapore (1.43; 95\%CI: 197 1.38-1.47) despite their southerly geographic locations. Further, mortality rate ratio in Singapore 198 (1.43, 95\%CI: 1.38-1.47) was significantly less than in Japan (1.54; 95\%CI: $1.48-1.59)$ and in 199 Hong Kong (1.57; 95\%CI: 1.52-1.62). Moreover, although East Asia spreads geographically, 200 Table 2 showed no significant changes in mortality rate ratios in $60+$ age groups were found among 201 the four regions. 
In the present study, trends in mortality rates of $\mathrm{CM}$ in four East Asian regions were analyzed using the GAM and the joinpoint regression method. Main general findings include: 1) significant growth in ASMRs in four East Asian regions; 2) mortality rate ratios were significantly greater in men compared to women in East Asian populations; and 3) mortality rate ratios were significantly greater in groups aged 60+ years compared to those aged 30-59 and 0-29 years in East Asian populations.

\section{Link with international studies}

Over the past several decades, considerable studies investigated mortality rates of $\mathrm{CM}$ in 2009). Conversely, trends in incidence and mortality in Asian populations have been overlooked. The present study aims to fill gaps and expand the discussion by investigating trends in mortality rates and the mortality rate ratios by gender and age.

Mortality rates of CM in some European countries and North America had leveled off since the 1990s; however, the results of this study suggested this may not be true based on recent researches

222 for Caucasian populations and this study for Asian populations. In the present study, ASMRs 
223

224

225

226

227

228

229

230

231

232

233

234

235

236

237

238

239

240

241

242

243

increased significantly in four regions of East Asia over the past six decades, with female

contributing greater AAPC than male in Japan, Korea, and Hong Kong. In the other region

worldwide, although mortality rate of CM leveled off in several regions, e.g. Spain (Cayuela et al.

2005) and Sweden between 1980s and 1997 (Cohn-Cedermark et al. 2000), more recent studies

found the mortality rates of CM increased worldwide, e.g. USA (Garbe \& Leiter 2009), Nordic

counties (Tryggvadottir et al. 2010), Brazil (Mendes et al. 2010), and Australia (Baade \& Coory

2005). For the age effects, older patients ( $>65$ years old) had significant growth in mortality rates

in some regions, e.g. South-Eastern European (Barbaric et al. 2016), Netherland (Hollestein et al.

2012), USA (Simard et al., 2012), and Australia (Baade \& Coory 2005). The updated trends in

mortality rates of $\mathrm{CM}$ varied in different regions globally. It is worth to note more regions had

reported increases in mortality rates after the leveled off of mortality rates of CM since 1990s

(Nikolaou \& Stratigos 2014). These latest studies challenged the efforts and our knowledge of improving survival rates of CM through effective protection and identifying risk factors.

Furthermore, the results of the present study showed mortality rate ratio of men were significantly greater than that of women in four regions in East Asia. Results were consistent with mortality rates reported in men and women in Caucasian populations (Bristow et al. 2013). Further, results indicated that older individuals had the greatest risk of mortality from CM in four East Asian regions. This is consistent with previous conclusion in other regions. A recently published study indicated a significant growth of mortality in Southern Europe in middle and older aged individuals (Barbaric et al. 2016). In USA, there has a high incidence of CM for patients older than 65 years 
244 (Simard et al. 2012). In New Zealand, Liang et al., (2010) showed the older men (> 59 years) had

245 the highest risk of developing CM (Liang et al. 2010).

246

247 UV radiation is as a key environmental risk factor for CM. The UV index, developed through an international effort, is a measure of the UV radiation on a scale from one to values greater than 11 .

Higher UV index values indicate a greater risk of skin damage; UV index value greater than two indicates needs for protection (WHO Library Cataloguing-in-Publication Data 2002). Due to the vast geographic spread of the four regions in this study, UV indexes varied, with higher UV index reported closer to the equator. Therefore, there was a UV index gradient from the southernmost region to the northernmost region in East Asia. In Singapore, the southernmost region $\left(1^{\circ} \mathrm{N}\right)$, the maximum UV index ranged from 10 to 13 (Ultraviolet radiation and the INTERSUN Programme, Available at http://www.who.int/uv/intersunprogramme/activities/uv_index/en/index3.html [accessed 4 July 2016]). In Hong Kong $\left(22^{\circ} \mathrm{N}\right)$, the reported maximum UV index was greater than 257 six in $69.8 \%$ of days over the past decade (Hong Kong Observatory, Available at http://gb.weather.gov.hk/wxinfo/uvindex/chinese/cfreq_dist.htm [accessed 4 July 2016]). The maximum UV index in Japan (using Tokyo as the location, $36^{\circ} \mathrm{N}$ ) ranged from 5 to 10 between March and September (Ultraviolet radiation and the INTERSUN Programme, Available at http://www.who.int/uv/intersunprogramme/activities/uv_index/en/index3.html [accessed 4 July 2016]). Thus, in East Asia, a UV index gradient exists among the four East Asia regions from Japan to Singapore. Moreover, the average ASMRs increased from the northernmost region to the southernmost region for both genders. This suggests the geographic gradient may play a role in 
265 relative risks in East Asia. This result was consistent with studies in other regions e.g. the Europe

266 (Crocetti et al. 2015). UV is considered one of the main environmental risk factor to developing

$267 \mathrm{CM}$, therefore, sun protection is as an effective way to reduce the risk of damaging skin (Guy et

268 al. 2015).

269

270

Limitations

271

272 There are several possible improvements of our study. Firstly, given the age distribution from the previous studies, we did not use the standard 5-year age group division to examine the trends in ASMRs of East Asia. Sng et al. (2009) reported CM incident rates in Singapore in two age groups: younger than 60 years, and older than 60 years. Luk et al. (2004) reported that $57.1 \%$ of CM patients in Hong Kong received a diagnosis at age 60 or greater, while only $6.3 \%$ received a diagnosis at age 30 or younger, and no data was reported for patients between the age of 50 and 60 years old. In addition, Hui et al. (2005) reported a mean age of 57.6 years for 32 Hong Kong CM patients. Given these information, ASMRs data was categorized into three age groups to allow for comparison to previous work. Thus, more will be carried out for more detail age groups.

Secondly, the coverage of data is limited for East Asia. Due to the lack of mortality data in other regions of East Asia, ASMRs were only analyzed for Japan, Korea, Hong Kong, and Singapore in this study. Although China has the largest population in the world, no long-term data were available recently. Furthermore, it is important to note that all four regions are high-income. The 
286 Gross Domestic Production per capita in Japan, Korea, Hong Kong, and Singapore was $287 \$ 36,194.40, \$ 27,970.50, \$ 40,169.50$, and $\$ 56,284.30$, respectively. Therefore, more data of CM in 288 the developing region are needed in the future.

Public health implication

Due to low incidence rates of CM in Asians populations, data on this topic were limited (Bellew et al. 2009). This study demonstrates there was more risk for mortality in men, older aged individuals $(60+)$, and populations with high UV indexes in four East Asian regions. In order to reduce the incidence and mortality of $\mathrm{CM}$, for the public, it is suggested to: 1) reduce UV radiation exposure; 2) increase sun protection; 3) avoid prevalent sunbed use (Wallingford et al. 2013); 4) increase public awareness/education (Buster et al. 2012; Gohara 2015); and 5) adopt screening and early diagnosis practices (Boniol et al. 2015; Crocetti et al. 2015; Tryggvadottir et al. 2010).

Although the CM mortality data in East Asian populations is limited, the significant increase in mortality rates identified in this study point to a need for increased attention and further study. Finally, it is vital to increase public awareness about the risks of CM and take action to reduce the incidence of CM.

\section{Acknowledgements}

We acknowledge the excellent work of Section of Cancer Surveillance, International Agency for 
306 Research on Cancer. We thank Prof. Peter Baade and the two anonymous reviewers for their 307 constructive comments that greatly enhanced this manuscript. We would also like to thank Laura 308 Beamish at the University of British Columbia for her assistance with English language and 309 grammatical editing of the manuscript, and Prof. Jian Shuai at the Jiangxi University of Traditional 310 Chinese Medicine for his assistance with statistical analysis.

311

312 
313

314

315

316

317

318

319

320

321

322

323

324

325

326

327

328

329

330

331

332

333

334

335

336

337

338

339

340

341

342

343

344

345

346

347

348

349

350

351

352

\section{Reference}

Baade P, and Coory M. 2005. Trends in melanoma mortality in Australia: 1950-2002 and their implications for melanoma control. Australian and New Zealand Journal of Public Health 29:383-386.

Baade P, Meng X, Youlden D, Aitken J, and Youl P. 2012. Time trends and latitudinal differences in melanoma thickness distribution in Australia, 1990-2006. International Journal of Cancer 130: 170-178.

Barbaric J, Sekerija M, Agius D, Coza D, Dimitrova N, Demetriou A, Diba CS, Eser S, Gavric Z, Primic-Zakelj M, Zivkovic S, Zvolsky M, Bray F, Coebergh JW, and Znaor A. 2016. Disparities in melanoma incidence and mortality in South-Eastern Europe: Increasing incidence and divergent mortality patterns. Is progress around the corner? European Journal of Cancer 55:47-55.

Bellew S, Del Rosso JQ, and Kim GK. 2009. Skin cancer in asians: part 2: melanoma. The Journal of clinical and aesthetic dermatology 2:34.

Bidoli E, Fratino L, Bruzzone S, Pappagallo M, De Paoli P, Tirelli U, and Serraino D. 2012. Time trends of cancer mortality among elderly in Italy, 1970-2008: an observational study. Bmc Cancer 12.

Boniol M, Autier P, and Gandini S. 2015. Melanoma mortality following skin cancer screening in Germany. BMJ open 5.

Bristow BN, Casil J, Sorvillo F, Basurto-Davila R, and Kuo T. 2013. Melanoma-related mortality and productivity losses in the USA, 1990-2008. Melanoma Research 23:331-335.

Buster KJ, You Z, Fouad M, and Elmets C. 2012. Skin cancer risk perceptions: A comparison across ethnicity, age, education, gender, and income. Journal of the American Academy of Dermatology 66:771-779.

Cayuela A, Rodriguez-Dominguez S, Lapetra-Peralta J, and Conejo-Mir JS. 2005. Has mortality from malignant melanoma stopped rising in Spain? Analysis of trends between 1975 and 2001. British Journal of Dermatology 152:997-1000.

Cohn-Cedermark G, Mansson-Brahme E, Rutqvist LE, Larsson O, Johansson H, and Ringborg U. 2000. Trends in mortality from malignant melanoma in Sweden, 1970-1996. Cancer 89:348-355.

Crocetti E, Mallone S, Robsahm TE, Gavin A, Agius D, Ardanaz E, Chirlaque Lopez M-D, Innos K, Minicozzi P, Borgognoni L, Pierannunzio D, Eisemann N, and Grp EW. 2015. Survival of patients with skin melanoma in Europe increases further: Results of the EUROCARE-5 study. European Journal of Cancer 51:2179-2190.

Duschek N, Skvara H, Kittler H, Delir G, Fink A, Pinkowicz A, and Waldhoer T. 2013. Melanoma epidemiology of Austria reveals gender-related differences. European Journal of Dermatology 23:872-878.

Garbe C, and Leiter U. 2009. Melanoma epidemiology and trends. Clinics in Dermatology 27:39.

Giblin AV, and Thomas JM. 2007. Incidence, mortality and survival in cutaneous melanoma. 
353

354

355

356

357

358

359

360

361

362

363

364

365

366

367

368

369

370

371

372

373

374

375

376

377

378

379

380

381

382

383

384

385

386

387

388

389

390

391

392

393

Journal of Plastic Reconstructive and Aesthetic Surgery 60:32-40.

Goh VH. 2005. Aging in Asia: A cultural, socio-economical and historical perspective. The Aging Male 8:90-96.

Gohara M. 2015. Skin cancer: an African perspective. British Journal of Dermatology 173:17-21. Guy GP, Jr., Thomas CC, Thompson T, Watson M, Massetti GM, and Richardson LC. 2015. Vital Signs: Melanoma Incidence and Mortality Trends and Projections - United States, 19822030. Mmwr-Morbidity and Mortality Weekly Report 64:591-596.

Hollestein LM, van den Akker SAW, Nijsten T, Karim-Kos HE, Coebergh JW, and de Vries E. 2012. Trends of cutaneous melanoma in The Netherlands: increasing incidence rates among all Breslow thickness categories and rising mortality rates since 1989. Annals of Oncology 23:524-530.

Hui S, Lau K, Leung C, Tang W, Yau K, Trendell-Smith N, Wong T, Chong L, and Lo K. 2005. Cutaneous melanoma: clinical features of 32 Hong Kong Chinese patients. Hong Kong $J$ Dermatol Venereol 13:130-140.

Kim H-J, Fay MP, Feuer EJ, and Midthune DN. 2000. Permutation tests for joinpoint regression with applications to cancer rates. Statistics in Medicine 19:335-351.

Koh D, Wang H, Lee J, Chia KS, Lee HP, and Goh CL. 2003. Basal cell carcinoma, squamous cell carcinoma and melanoma of the skin: analysis of the Singapore Cancer Registry data 1968-97. British Journal of Dermatology 148:1161-1166.

Lasithiotakis K, Leiter U, Meier F, Eigentler T, Metzler G, Moehrle M, Breuninger H, and Garbe C. 2008. Age and gender are significant independent predictors of survival in primary cutaneous melanoma. Cancer 112:1795-1804.

Liang JJC, Robinson E, and Martin RCW. 2010. Cutaneous melanoma in New Zealand: 20002004. Anz Journal of Surgery 80:312-316.

Luk N, Ho L, Choi C, Wong K, Yu K, and Yeung W. 2004. Clinicopathological features and prognostic factors of cutaneous melanoma among Hong Kong Chinese. Clinical and Experimental Dermatology 29:600-604.

Makredes M, Hui SK, and Kimball AB. 2010. Melanoma in Hong Kong between 1983 and 2002: a decreasing trend in incidence observed in a complex socio-political and economic setting. Melanoma Research 20:427-430.

Mendes GLQ, Koifman RJ, and Koifman S. 2010. Mortality Frequency and Trends Attributed to Melanoma in Brazil from 1980-2005. Journal of Toxicology and Environmental HealthPart a-Current Issues 73:850-857.

Nikolaou V, and Stratigos AJ. 2014. Emerging trends in the epidemiology of melanoma. British Journal of Dermatology 170:11-19.

Oizumi K. 2013. Aging in Asia. When the Structure of Prosperity Changes. Public-Interest Incorporated Foundation, Oriental Life Insurance Cultural Development Center, Tokyo, Japan

R Core Team. 2016. R: A language and environment for statistical computing. R Foundation for Statistical Computing, Vienna, Austria. 2015. http://www.R-project.org.

Segi M. 1969. Cancer mortality for selected sites in 24 countries: Japan Cancer Society. 
394

395

396

397

398

399

400

401

402

403

404

405

406

407

408

409

410

411

412

413

414

415

416

417

418

419

420

421

422

423

424

425

426

427
Simard EP, Ward EM, Siegel R, and Jemal A. 2012. Cancers with increasing incidence trends in the United States: 1999 through 2008. CA-a Cancer Journal for Clinicians 62:118-128.

Sneyd MJ, and Cox B. 2013. A comparison of trends in melanoma mortality in New Zealand and Australia: the two countries with the highest melanoma incidence and mortality in the world. Bmc Cancer 13.

Sng J, Koh D, Siong WC, and Choo TB. 2009. Skin cancer trends among Asians living in Singapore from 1968 to 2006. Journal of the American Academy of Dermatology 61:426432.

Tanaka H, Tsukuma H, Tomita S, Ajiki W, Kitagawa T, Kinoshita N, Yoshikawa K, and Oshima A. 1999. Time trends of incidence for cutaneous melanoma among the Japanese population: an analysis of Osaka Cancer Registry data, 1964-95. Journal of epidemiology / Japan Epidemiological Association 9:S129-135.

Tryggvadottir L, Gislum M, Hakulinen T, Klint A, Engholm G, Storm HH, and Bray F. 2010. Trends in the survival of patients diagnosed with malignant melanoma of the skin in the Nordic countries 1964-2003 followed up to the end of 2006. Acta Oncologica 49:665-672.

United Nations. 2015 Department of Economic and Social Affairs Population Division United. World Population Prospects: The 2015 Revision, Key Findings and Advance Tables. Working Paper No ESA/P/WP241.Available at https://esa.un.org/unpd/wpp/publications/files/key findings_wpp_2015.pdf (accessed 4 July 2016)

Wallingford SC, Alston RD, Birch JM, and Green AC. 2013. Regional melanoma incidence in England, 1996-2006: reversal of north-south latitude trends among the young female population. British Journal of Dermatology 169:880-888.

WHO Library Cataloguing-in-Publication Data. 2002. Global solar UV index: a practical guide. Available at http://www.who.int/uv/publications/en/GlobalUVI.pdf(accessed 4 July 2016)

World Bank Datasets. $2016 . \quad$ Available at http://data.worldbank.org/indicator/SP.POP.65UP.TO.ZS (accessed 4 July 2016)

World Health Organization, health statistics and information systems, mortality database, Available at http://www-dep.iarc.fr/WHOdb/WHOdb.htm (accessed 4 July 2016)

Wood S. 2006. Generalized additive models: an introduction with R. CRC Press.

Zeng H, Zhang S, Zheng R, Zhou X, Li M, Wang N, Li Q, and Chen Z. 2012. Analysis of incidence and mortality of cutaneous melanoma from 2003 to 2007 in China. China Cancer 3:183189 (in Chinese with English abstract). 